\title{
Landscape Image Conceptual Model of Forests in China
}

\author{
Chen Wang, Fen Luo*, Xueli Li and Yongde Zhong \\ College of Tourism, Central South University of Forestry \& Technology; Changsha410004, Hunan, China; \\ 2274223354@qq.com (C.W.); 2275249502@qq.com (L.X.); adely@csuft.edu.cn (Y.Z.) \\ * Correspondence: e-mail: fen.1@csuft.edu.cn; Tel: +86-180-0842-1922
}

\begin{abstract}
The landscape image is the bridge of communication between people and forests, and the cut point of the supply-side reform of forest tourism products. The research collected 140 copies in total of forest landscape image drawings from non-art-major graduate students by randomly sampling during April and May, 2018, and constructed the landscape image conceptual model of forest by utilizing the landscape image sketching technique. The results showed that (1) In regard to linguistic knowledge, the natural landscape elements for instance, herbaceous plants, terrains, creatures, water and sky, and the broad-leaf forest objectively reflected not only the real forest landscape and the local native vegetation, but the variation of forest species with little attention. (2) On the perspective of spatial view, the sideways view indicated that graduate students preferred to watch forests at a moderate distance externally and few looked at forests internally. (3) In the view of self-orientation, the objective landscape indicated that graduate students preferred to demonstrate forest landscapes, they did not realize to interact with the environment. (4) On the aspect of social meaning, the scenic view and forest structure stated that graduate students preferred rural forest landscapes, not
\end{abstract}


significantly for other special interests for forest. In conclusions, (1) the forest is thought to be a feature of people's life world and of rural scenes around homes, not an objective perception of the forest. (2) The forest is regarded as an important habitat for animals and a limited resource for people's life, production and recreation needs, into which people will go only to meet such needs. (3) The natural values of forests, like the ecology and aesthetics, etc. get more attention, while the social values of forests, like the life, production and culture receives rather low attention.

Keywords: Forest recreation; Forest landscape; Landscape image; Landscape Image Sketching Technique

\section{Introduction}

The beautiful ecological environment is an important expectation of people for the happy life in the new era [1]. In the context of China's way of utilization of forests transforms from a production space to a tourism consumption space and further to a strategic space for the supply of the ecological public goods of forests [2], the forest tourism turns into the third main way to use the forest following the wood production and under-forest economy, and is becoming the pillar industry of forestry in each country. Take USA as an example, in 2000, the forest service programs of USA created an extra value of $\$ 130.7$ billion, accounting for almost $2 \%$ of the country's GDP, in which the value created by the forest tourism, mainly consisting of recreations and sports, amounted to $\$ 97.8$ billion, accounting for almost $75 \%$ of the output value of all the forest service programs, which made it No. 1 contributor to the 
United States forestry incomes[3]. Under the guidance of the forestry development theory of "lucid waters and lush mountains are invaluable assets" in the new era, the in-depth research on the public perception of forests is not only the premise for people to go into, understand and experience the forest, but also the fundamental research work to practice the forestry development theory in the new era.

Since the introduction of the topic, "forests play a vital role in balancing the development of human beings" on the 13rd World Forestry Congress in 2009, the approach of perceiving the forest from the perspective of landscape has become one of the hotspots in the research of the service function of the forest ecological system, the main point of which is to focus on public understandings about the physical features of forest landscapes and on the perception and interpretation of the information the public receives, so as to understand in-depth what the public concern about when they watching forests and how they regard forests as landscapes. Studies have shown that the cognitive research on the forest mainly includes implicit emotions, spiritual or mysterious implications [4, 5], and public perceptions of the "forest" in different cultural contexts $[6,7]$, which focuses on the viewpoint of people towards the physical characteristics of forest landscapes and the understanding of people about the information received by them [8]. The research primarily uses quantitative research methods, such as the photo grading method [9], the method of semantic differential [10], the Delphi method [11], the field interview [12], the landscape image sketching technique [13], and the creation of multidimensional cognition and value evaluation models $[14,15]$. The study of China's scholars on the perception of forests mainly concentrates on the forest aesthetics [16], the forest landscape quality evaluation [17], the exploration of multi properties of forests[18], etc., and the methods 
often used to create the evaluation system of in-forest landscapes or to evaluate the quality of the in-forest landscapes include the Analytic Hierarchy Process (AHP) [19], the Analytic Network Process (ANP) [20], and the Scenic Beauty Assessment Method (SEB) [21], etc.

Further studies have shown that there are three issues in the research of the forest perception: (1) emphasizing the natural ecological property of forests while neglecting the way to research people's perception of forests from the perspective of social sensing during the interaction between people and forests; (2) using mainly such traditional visual stimulation approaches as the landscape photo and the field visual assessment, etc., while seldom using the landscape image sketching technique from the East; (3) making existing landscape sketching technique as the supplement for the data of language and emphasizing the frequency of drawing elements, while seldom involving the correlation between the composing element and the main body, as well as between the elements, in the key sketches in the research. Studies have shown that the landscape drawing is the representation of the landscape impression by the research object, and can vividly reveal what people see in the forest and how they look at the environment they are in, which in the essence is the mapping of the correlation and information between the human body and the environment around [8]. In recent years, the introduction of the landscape image theory that organically combines the relation between the landscape element, the subject's viewpoint, the self-orientation in the landscape composition and the verbal description of the drawing's significance of the landscape image given by the research object has made the landscape sketching technique to be a possible option to study the landscape image.

The landscape image is the bridge of communication between people and forests, and is 
the cut point of the supply-side reform of forest tourism products, therefore, in the guidance of the landscape image theory and by choosing the graduate students with a certain degree of forest and social cognitive and drawing abilities as the research object, and the landscape image sketching technique as the research method, this paper has studied the graduate students' perception of the forest landscape from four aspects, namely the linguistic knowledge, the spatial view, the self-orientation and the social meaning, and created the forest landscape image model for graduate students, which has certain theoretical innovation values and can provide new possible approaches for China's supply-side reform of forest tourism products and forest educations.

\section{Research Design}

\subsection{Landscape Image Sketching Techniques}

As a kind of psychological image, the environment image is a presentation induced from the external environment by the human brain, a combination of the direct feeling and the past experience or memory, so as to acquire the environment information, then to instruct people's environmental behaviors [22]. The landscape image is people's perception and experience from certain spaces, and a comprehensive result of the observer's subjective understanding about the information received from the landscape object, such as the morphological structure, the individual characteristic and meaning, etc [23]. In fact, the landscape image is resulted from the bi-directional effect of the observer and the landscape he/she stays in. The observer interprets the specific landscape based on his/her experience, knowledge and direct feelings, at the same time connects it to his/her physical and mental needs to acquire happy experiences. Even though the experience acquired by the observer varies depending on his/her own experience, 
knowledge and feelings, it will finally combine into a common and collective psychological image, i.e. the landscape image.

Based on the difference between environment image and landscape image, this paper has chosen landscape image as the key concept of the research. Firstly, the landscape image includes spaces (spatial view) and symbols (linguistic knowledge); secondly, the landscape image is inseparable from the standing point of the observer. Thirdly, we assume the environment has a common social meaning when the landscape is homogenized in a social group. The integration of the spatial view, linguistic knowledge, self-orientation and social meaning is completed through the experience and communication of the group. It's possible to integrate different landscape images into the standardized landscape watching mode by enlarging the communication process among a social group. Meanwhile, the landscape image can standardize the individual perception and the social construction as it is formed in a certain cultural frame. Therefore, the landscape image model is established on the basis of four factors, namely the linguistic knowledge, the spatial view, the self-orientation and the social meaning (as shown in Figure 1). The landscape image includes spaces and symbols (the spatial view and the linguistic knowledge), as well as the individual and social aspects (the self-orientation and the social meaning) of the landscape. Therefore, the landscape image is in the center of the square model and includes all the elements. This theoretical model embodies the landscape image so as to make it possible to research people's perception of forests with the sketching techniques. 


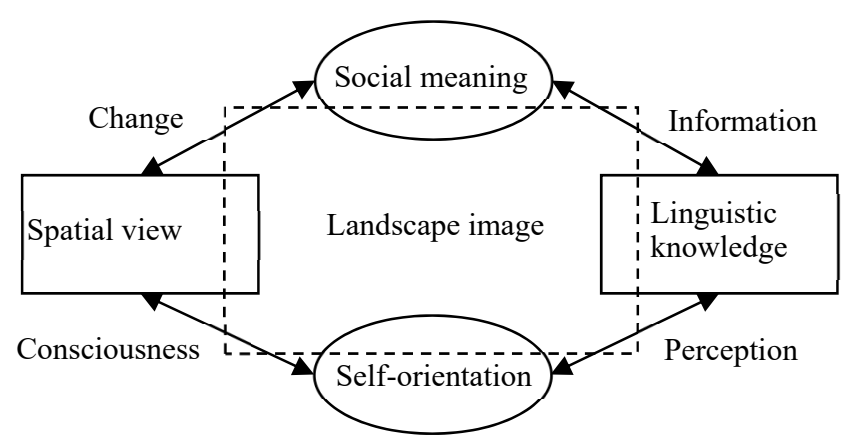

Figure 1. Diagram of the landscape image

(1) The linguistic knowledge refers to use languages and words to describe landscape elements, which is the first step for the painter to classify the landscape element in the drawings with language descriptions and drawings [24]. The linguistic knowledge mainly includes landscape elements and forest types. There are nine types of landscape elements in all, namely the herbaceous plants (including jungles, flowers, mushrooms, fruits and fallen leaves), terrains (including mountains, hills and various landform), creatures (including animals, birds and insects), water (rivers, streams, ponds, lakes and waterfalls), artificial objects (including signboards, benches, trash cans, houses and cars), people (including oneself and others), sky (including the sun, cloud, moon and star), brightness (meaning the sunlight goes through the leaves and shines on the ground), etc. Furthermore, based on the differences in trees and symbolic shapes of leaves, the forest can be divided into four types: the needleleaf forest, the broadleaf forest, the mixed forest and bamboo forest. Among them, the needleleaf forest is symbolized by the shape of Christmas trees or triangle-shaped crowns; the broadleaf forest is symbolized by round trees or leaves; the mixed forest is composed of various symbols like needleleaf trees, broad leaf trees, etc.; the bamboo forest is symbolized by long and thin trunks 
with joints. Furthermore, a few of the forests are classified as the unknown type as it's hard to decide the forest type only with the outline of mountains or trunks; the stumps above the ground, trees having been cut down and naturally fallen down are classified as the upside-down tree.

(2) The spatial view refers to that the shape or combination of every landscape element in the drawings can determine the viewing angle and distance of the observer [25]. The drawings of the forest landscape image can be divided into three types of short, medium and long distances according to the size and texture of the tree symbols in the them. Among them, the medium distance includes two views: the sideways view and the bird's-eye view. Therefore, the viewing angle of a landscape drawing can usually be divided into four kinds of images: the close-up view, the sideways view, the bird's-eye view and the distant view. Among them, the close-up view is to watch the forest from inside and is the special description of trunks and certain landscape elements. The sideways view is to represent the structure of the forest edge or forest with the shape of a whole tree. The bird's-eye view watches the forest from up to down and emphasizes the horizontal structure and the broadness of forests. The distant view often shows the outline of mountains only, which makes it difficult to distinguish the crown shape of the tree growing on the mountain.

(3) The self-orientation of the subject is represented by the relation between the standing point of the subject and various landscape elements in the drawing and it is in fact a kind of interactive relation between people and the environment [25]. The self-orientation can usually be divided into four types: the single object, the objective landscape, the surrounding place and the scenic place. Among them, the single object means there is only one kind of image or image collection in the drawing; the objective landscape means that the combination of various 
landscape elements composing a landscape drawing only demonstrates the objective relation between various landscape elements, neither reflecting the spatial continuity, nor indicating the viewing point of the observer; the surrounding place reflects the position of the observer in the forest; the scenic place refers to that the subject overlooks the environment of the forest at a greater distance, and can be regarded as the combination of the objective landscape and the viewing point.

(4) The social meaning that the painter has endowed with the forest can be interpreted based on the verbal data of the painter, the landscape elements in the drawing and the selforientation ${ }^{[26]}$. The object in the drawing not only reflects the personal interest of the painter, but also indicates the specific social meaning that the painter has endowed with it. Considering the landscape element (the linguistic knowledge), the distance and the perceptive (the spatial view) and the position of the subject in the forest (the self-orientation), the social meaning can be divided into eight types: the forest structure, the scenic view, the recreation space, the forest operation and the life world.

\subsection{Data Collection and Processing}

This research has randomly selected 50 graduate students of non-fine-art or non-art majors in such places as the university library, the classroom, and the dormitory, etc. of Central South University of Forestry and Technology, Central South University and Hunan Women's University respectively in the early morning or at the noon in April to May 2018, which all locate in Changsha, Hunan Province, to collect 140 copies of forest landscape image drawings, in which 131 copies are valid. The research has shown that women accounted for $63 \%$ and men accounted for $37 \%$ of all the respondents; sophomores were the main group that accounted for 
$54 \%$, and the freshmen and junior students accounted for $17 \%$ and $29 \%$ respectively; those students whose native places are in southern China were the main group that accounted for $65 \%$, and $30 \%$ of the respondents have their native places in Hunan.

The main research procedures are as follows: firstly, conduct a preliminary communication with the respondent to make sure the research object and basic information (e.g. gender, major, grade, native place, etc.); secondly, raise the following question to the respondent: "what can the word 'forest' remind you of when you hear it?"; thirdly, ask the respondent to draw the forest in his/her mind on an A4 paper in 15 minutes and, for the landscape element he/she can't draw, write a circle together with the name of that element instead; fourthly, ask the respondent to describe what landscape elements are included in his/her drawing and what the social meaning is briefly. Classify the landscape image drawings collected from the respondents according to four aspects, namely the linguistic knowledge, the spatial view, the self-orientation and the social meaning, as well as 31 elements, and count the landscape image drawings containing the elements as " 1 ", and those not containing any element as " 0 ", at the same time, create the database of graduate students' landscape image drawings in the Excel spreadsheet.

\section{Results and Analyses}

\subsection{Analyses of the Linguistic Knowledge}

Statistics have shown that the herbaceous plants and sky have the highest frequencies of occurrences, which are $64 \%$ and $60 \%$ respectively; the creatures, water, trails, terrain and artificial object have relatively high frequencies of occurrences, which are $42 \%, 37 \%, 34 \%$ and $24 \%$ respectively; the people and brightness get the lowest frequencies of occurrences, which 
are $8 \%$ and $3 \%$ respectively (Figure 1). The research has discovered that the higher frequencies of occurrences of the herbaceous plants, terrain, creatures, water and sky, and the less description of such human landscape elements as the artificial objects and trails, etc., reveal that the graduate students' perception of the forest landscape mainly focuses on natural landscapes, and they express their love for the nature through representations of such natural landscape elements as the mountain, water, plant, animal and sky, etc. in the drawings. The frequency of description for brightness is rather low as the brightness can only be observed by going into the forest and graduate students often present only such an objective background as the sky.

On the aspect of forest types: the broadleaf forest $>$ the mixed forest $>$ the needleleaf forest $>$ the bamboo forest $>$ the unknown type $>$ the upside-down tree (Table 1). The research has discovered the main reason for the high frequency of occurrences of the broadleaf forest is that the respondents mostly live in areas of subtropical evergreen broadleaf forests, and the broadleaf forest is most commonly seen around the dwelling places related to their life, study and recreation activities, alongside the road and in the park, etc., which affects the respondents' preference for forest types and which also reflects the local native vegetation to a certain degree. The frequency of descriptions of the mixed forest is not high, which indicates the tree type is important to experts, it however has limited attraction for the public who don't have a clear idea about the forest type [27]. The bamboo forest has received low frequency of occurrences, which is mainly because many graduate students don't regard the bamboo forest as a kind of forest type, therefore, they have neglected bamboos when drawing trees. All these results have shown that people's perception of the forest can be affected by multiple factors, such as their dwelling places, the living environment and the restriction of their cognitive abilities. Furthermore, the 
upside-down tree has the lowest frequency, which not only demonstrates that the graduate students don't like withered and fallen trees, but also indicates they go to the forest less frequently and don't care about the nature and ecological environment.

Table 1. Landscape element and forest types

\begin{tabular}{cccc}
\hline Classification & Sub-classification & Number & Percentage \\
\hline \multirow{2}{*}{ Natural landscape } & Herbaceous plants & 84 & $64 \%$ \\
& Terrain & 45 & $34 \%$ \\
& Creatures & 55 & $42 \%$ \\
& Water & 48 & $37 \%$ \\
& Brightness & 3 & $2 \%$ \\
Human landscape & Sky & 32 & $47 \%$ \\
& Trails & 62 & $28 \%$ \\
& Artificial objects & 37 & $24 \%$ \\
& People & 31 & $6 \%$ \\
& Mixed forest & 8 & $26 \%$ \\
& Needleleaf forest & 34 & $10 \%$ \\
& Broadleaf forest & 13 & $60 \%$ \\
& Bamboo forest & 78 & $5 \%$ \\
& Unknown & 6 & $8 \%$ \\
& Fallen trees & 10 & $2 \%$ \\
\hline
\end{tabular}

\subsection{Analyses of the Spatial View}

Based on the spatial view, the drawing of the forest landscape image can be divided into four types: the close-up view, the sideways view, the bird's-eye view and the distant view. Statistics have shown that the frequency of the description of the sideways view by graduate students ranks first (accounting for $73 \%$ ), such as in the drawings of the whole tree and the broadleaf tree (Figure 2a); the frequency of the distant view ranks second (accounting for 32\%), such as in the drawings of only three mountains and a tree with blurred crown (Figure 2b); the frequency of the bird's-eye view is rather low (accounting for 16\%), such as in the drawings with a river as the boundary and a pine tree forest on the upper and lower side respectively 
(Figure 2c); the frequency of the close-up view is the lowest (accounting for $7 \%$ ), such as in the drawings on which the texture of the trunk and the flower can be seen clearly (Figure 2d). (Note: the total sum does not equal to 1 as a drawing is composed of landscape elements of different viewing points and parts of the data are duplicated).

The research has shown that the drawings are dominated by sideways views with only a few complete broadleaf or needleleaf trees and without descriptions of the wooded forest landscape, which are similar to the greeneries around houses and the roadside tree landscape on both sides of the road, as most of the respondents often do not think of wooded forests when hearing the word "forest", but they prefer scattered tree spices [28], which indicates that many respondents watch the forest at a medium distance from outside and few look at the forest from inside, thus the broadness of the forest is neglected.
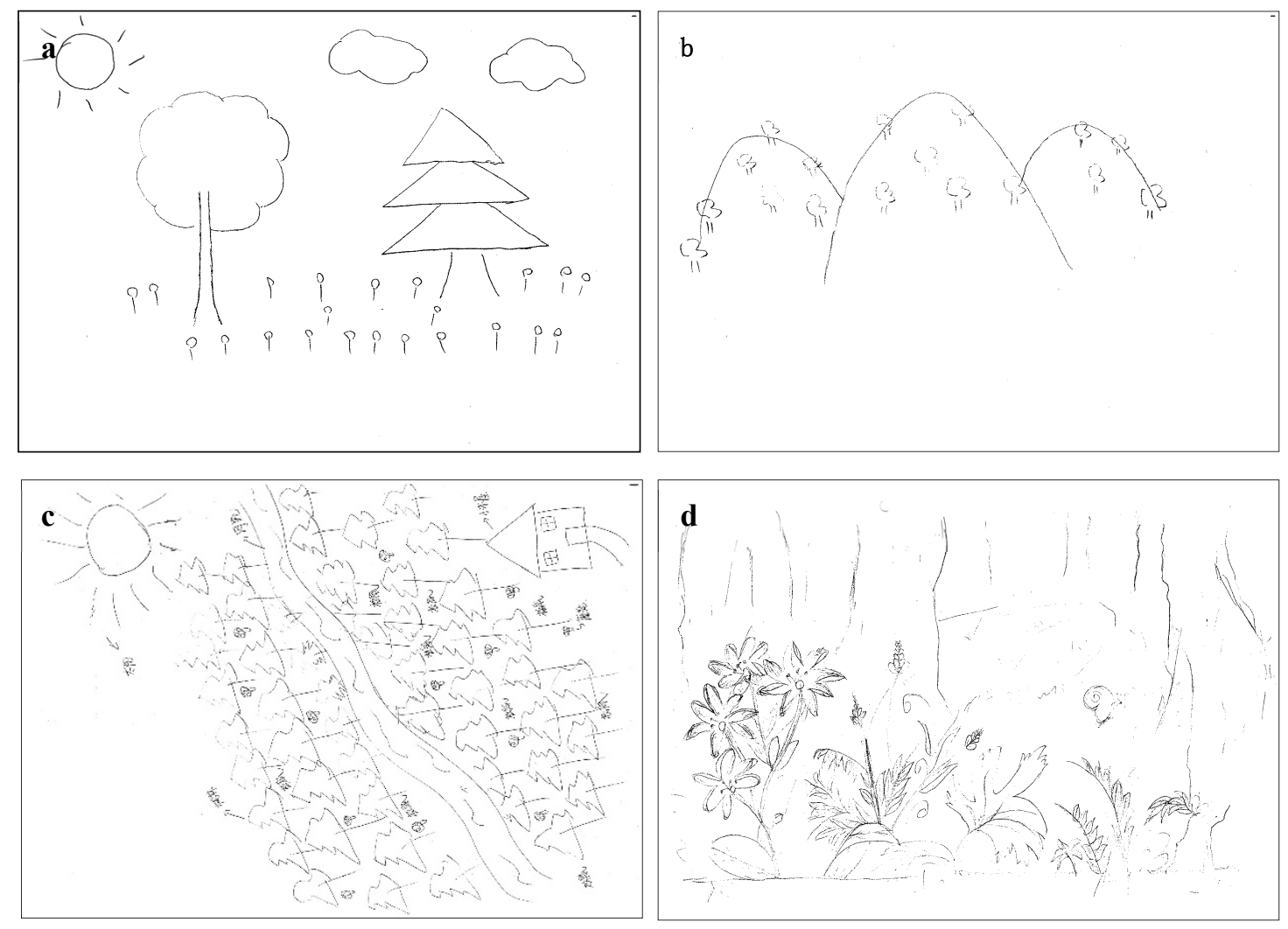

Figure 2. Classification of spatial views: (a) sideways view; (b) distant view; (c) bird's-eye view; (d) closeup view. 


\subsection{Analyses of the Self-orientation}

Statistics have shown that the frequency of the description of the objective scene by graduate students ranks first, accounting for $73 \%$, such as those drawings composed of natural landscape elements like trees, grasses, mountains and rivers (see Figure 3a); the frequency of the description of the surrounding place ranks second, accounting for $17 \%$, in which the graduate students have placed the road in the center of the drawing with featured trunks on both sides of it to indicate he/she is on the road (see Figure 3b); the frequency of the description of the single object ranks third, accounting for $7 \%$, for example in those drawings that only one type of tree can be seen (see Figure 3c); the frequency of the description of the scenic place is the lowest, accounting for only $4 \%$, for example in those drawings that there are not only the objective landscape that is composed of trees, grasses, bridges and lakes, but also a figure standing on the bridge and looking into the distance to indicate his/her viewing point (see Figure $3 d)$.

The research has discovered that there are more drawings describing the single object than those describing the objective scene, which indicates graduate students prefer the combination of various natural landscapes when drawing the forest landscape. It is further indicated that graduate students normally consider only the natural attributes of the forest and do not realize the interaction between himself/herself and the forest environment, thus he/she seldom place himself/herself inside the forest to reflect his/her position in it, and rarely describe the surrounding place and the scenic place. 


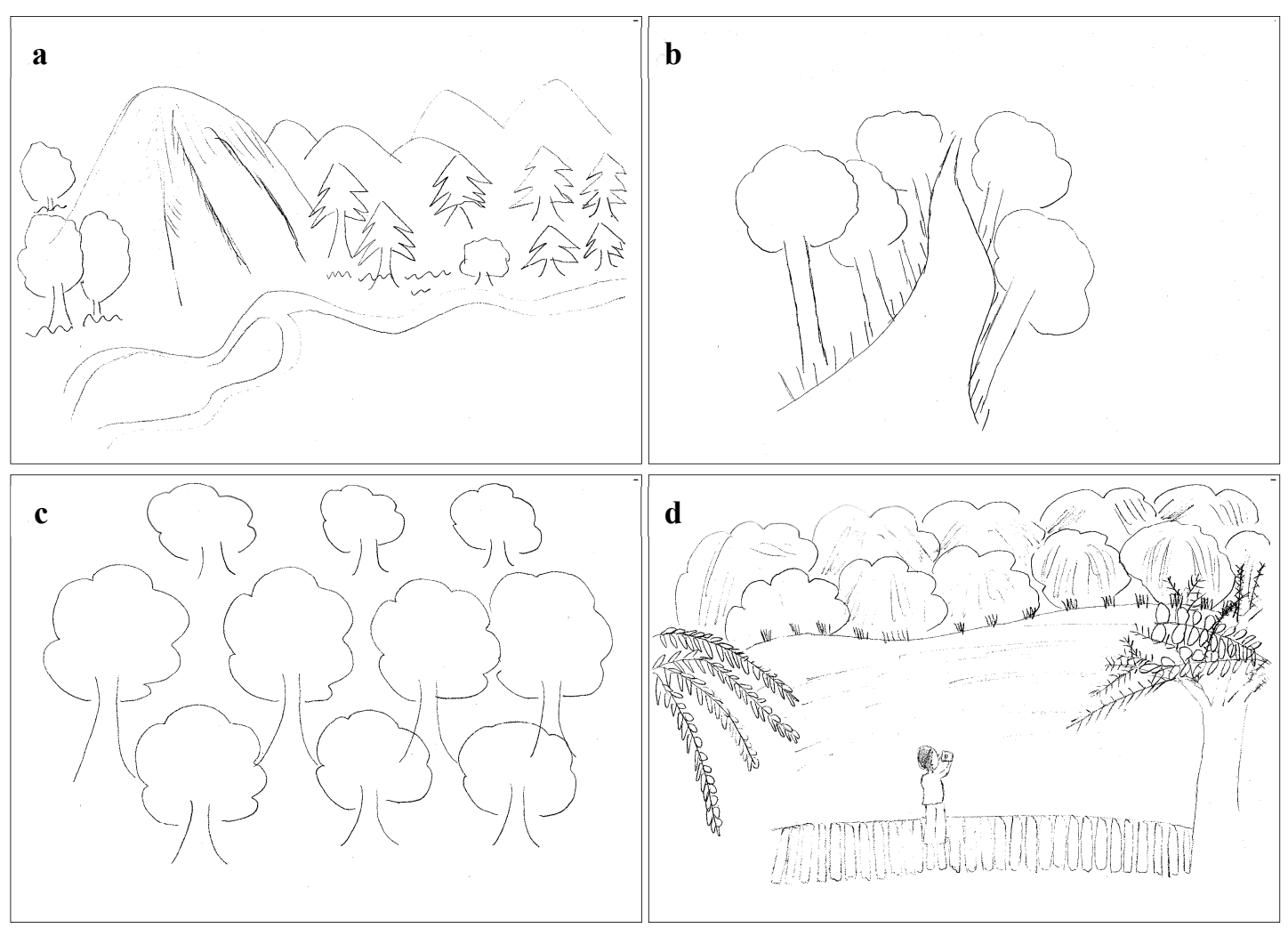

Figure 3. Classification of the self-orientation: (a) objective scene; (b) surrounding place; (c) single object; (d) scenic place.

\subsection{Analyses of the Social Meaning}

The analysis of the social meaning can reveal the respondent's interest in, and preference for, the forest, i.e. what he/she likes to do in the forest. Statistics have shown that, firstly, the frequencies of the descriptions of the scenic place and the forest structure are very high, accounting for $25 \%$ and $23 \%$ respectively; secondly, the frequencies of the ecological system, the recreational space, and the life world are high, accounting for $18 \%, 16 \%$ and $15 \%$ respectively; then the frequencies of the natural resources and the symbolic places are rather low, accounting for $5 \%$ and $4 \%$ respectively; furthermore, the frequency of the drawing of the forest operation image only accounts for $2 \%$.

The scenic view is similar to the objective scene or the scenic place in that it creates a beautiful forest drawing by making the close-up view and the sideways view as the front end landscape, while making the distant view (terrain) as the background, and is the expression of 
the painter's tastes and feelings about the landscape (see Figure 4a). The forest structure is embodied in the structure of forest vegetation with no description about how to use the forest and other types of forest elements are even less (see Figure 4b). The ecological system refers to an idealized objective scene including many kinds of plants and animals, such as various trees, grasses, rabbits, snakes and birds, etc. (see Figure 4c). The recreational space mainly refers to the surrounding place for recreational activities, which includes the trail for a walk in the forest (Figure 4d). The life world refers to settlements around the forest, such as those forests having houses in them (Figure 4e). The natural resources are mainly represented by the nontimber resources on the ground inside the forest, such as mushrooms and bamboo shoots, etc. under trees (Figure 4f). The symbolic place is generally composed of single object landscapes, such as an ancient tree or a symbolic landscape that usually leaves a deep impression on people. In the drawings, the painter often uses the close-up view to represent it, for example, a drawing of the Heaven's Gate Cave of Zhangjiajie City (Figure 4g). Furthermore, the forest operation refers to the diagram of the operation method of the forest industry. For example, the forest tree cutting (Figure 4h). 

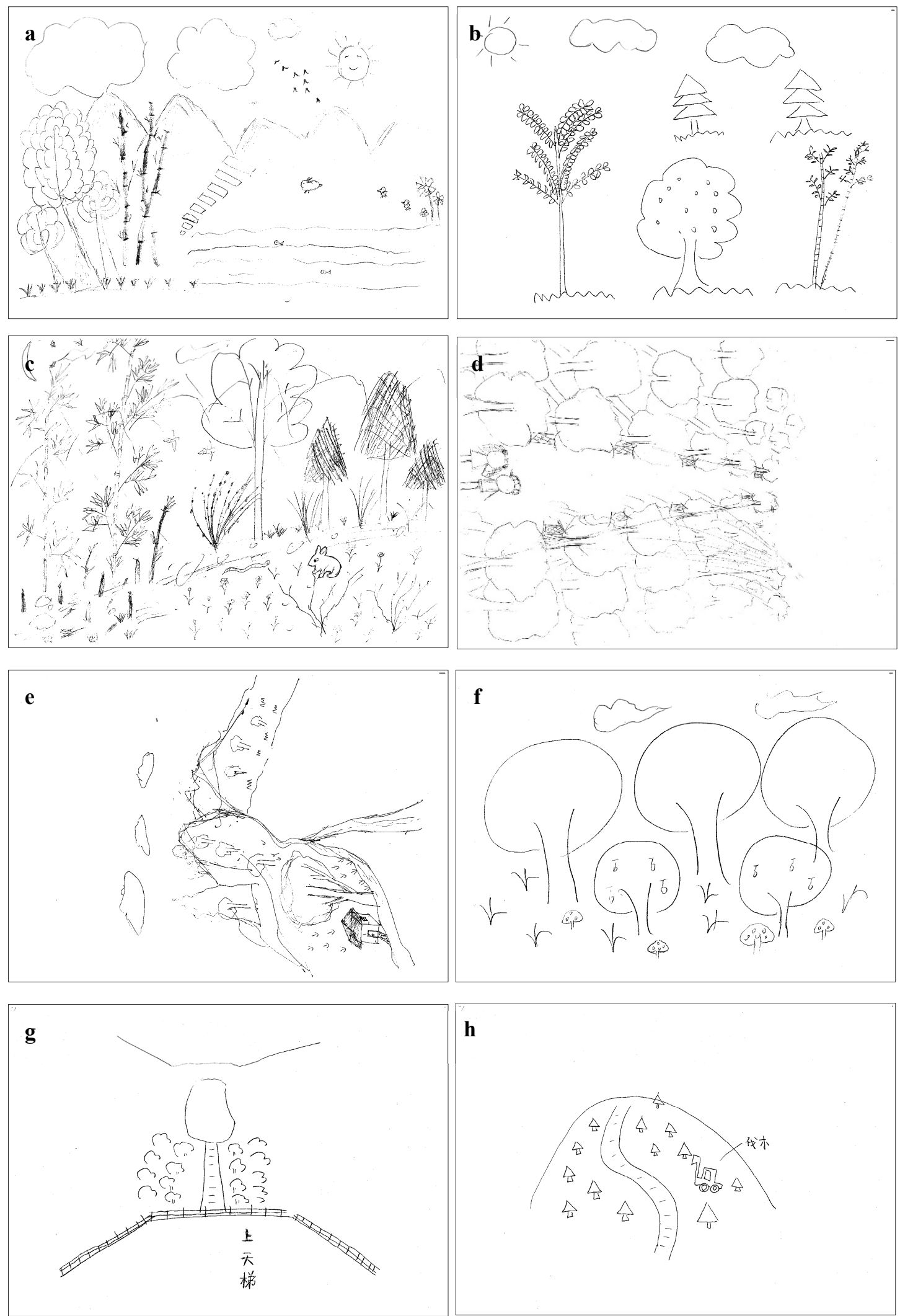

h

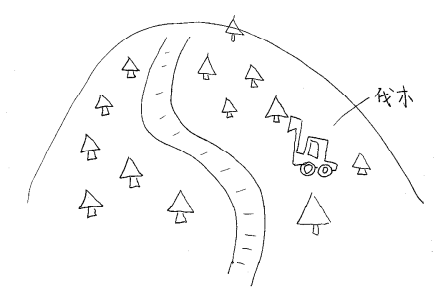

Figure 4. Classification of 'social meaning': (a) scenic view; (b) forest structure; (c) ecological system; (d) recreational space; (e) life world; (f) natural resources; (g) symbolic place; (h) forestry operation.

Further studies have shown that graduate students will think of trees when hearing the 
word "forest", and will include not only the symbol of a tree, but also other natural elements like streams, lakes, animals and non-timber resources, etc., which indicates they think there are plentiful landscape elements inside the forest and they prefer the combination of various landscape elements, including the more popular combinations of trees and fields, grasses, especially the element of water [29], resulting in more drawings of the forest structure and the ecological system. Many graduate students prefer to use mountains as backgrounds when drawing forests so as to depict a very beautiful rural forest landscape, which has resulted in the high frequency of the scenic view drawings. In the drawings, there have appeared houses with chimneys, which indicates graduate students have unconsciously regarded the rural landscape as the forest landscape, at the same time, the scattered distribution of urban green spaces indicates forests are closely connected to buildings [30], which have resulted in many drawings describing the life world. In addition, most of the respondents have thought of the old-growth forest when hearing the word "forest", and seldom have connected it to the forest scenic area, and as they have gone into the forest for only a few times and have not got a deep impression of the forest landscape, there is a small number of drawings of the symbolic place, however, the occurrence of the trail formed by people passing through the place habitually has increased the frequency of occurrences of the recreational space instead of the description of various other recreation facilities, which demonstrates some people might have undervalued the recreational attributes of the natural space [31], and such an evaluation from them on the natural environment might be partially because they have not got positive experience in the past or they cannot acquire interesting experience when getting in touch with the nature [32]. The frequency of occurrences of the drawings of natural resources is low as graduate students usually seldom 
climb up the mountain to pick up edible fungus and berries, etc. There are very few drawings describing the forest operation either, because during the transition of forest functions from the timber production to the supply of public products, there is hardly no opportunity to get in touch with the forest industry normally and few people are familiar with it.

\section{Discussions}

On the aspect of the linguistic knowledge, there are many drawings describing the broadleaf forest, which has reflected the type of the native vegetation in southern China to some extent, and similar studies have also indicated that the public of Russia and Japan prefer the mixed forest and the broadleaf forest respectively $[8,14]$. The reasons are as follows: firstly, the cultural and geographical differences have resulted in different preferences for the type of tree species [33]; secondly, the living environment, familiarity [34] and landscape dependency [35], etc. have certain effects on them as most of the respondents are living in subtropical evergreen broadleaf forest areas where the broadleaf forest is most common in the zone of vegetation around main activity spaces like houses, schools, etc. In addition, the high or low frequency of visiting the forest also affects people's cognition of the forest landscape [28], for example, the Chinese do not prefer the fallen tree, while the Japanese are just the opposite. As of 2010, Japan has established 3,700 Nature Schools which have perfected the forest education system that combines the popular science education of forest and curriculum teaching for teenagers and graduate students, and researches have shown that those who have received the forestry education demonstrate richer forest knowledge and are much more likely to get closer to the nature [36]. Currently, China's popular science education of forest is gradually getting 
people's attention, it is however in the stage of valuing forms while neglecting contents, enriching facilities while lacking curricula, making eye contact while missing interaction, and has not developed a complete forest education system even though a series of nature education center have been established on the base of forests and wetlands, therefore, the Chinese know relatively less about the forest knowledge [37].

On the aspect of landscape elements, China's graduate students prefer to describe such natural landscape elements as the herbaceous plants and sky, while studies have shown that the Japanese prefer such human landscape elements as the people, trails and brightness [26]. The reason for this is that the forest is always interpreted as a natural space in China, while it is perceived to be a recreational space in Japan [37]. All the time China's forest tourism focuses on the forest ecotourism and has only a few deep forest cognition modes like the forest research and study, as well as the nature education, etc., therefore, people's perception of the forest is defined to be a scenic natural space. The focus on the brightness is the result of the careful observation of the light variation in the forest, which indicates that China's graduate students frequently have contact with, get an in-depth perception of and establish a close connection with the natural environment of the forest $[38,39]$, and which contrarily proves that China's graduate students visit the forest at low frequencies and do not know the forest environment very well.

On the aspect of the spatial view, the sideways view is an important representation of the forest spatial view and does not demonstrate the broadness of the forest, which indicates the observer is at a certain distance away from the forest and the forest has a poor accessibility. Previous research pointed out that the graduate students from Irkutsk and Kamchatka Peninsula 
of Russia have used the bird's eye view more frequently, those from Moscow have used the close-up view and the sideways view more frequently, and those from Japan have used the close-up view and the bird's eye view more frequently [8, 14]. Further researches have pointed out that there are two kinds of affecting factors to the forest spatial cognition: firstly, the distance and the accessibility to the forest [40]; secondly, the terrain of the area that the forest belongs to [41]. The high frequency of occurrences of the sideways view indicates that the observer is at a certain distance away from the forest and has difficulties in accessing to it, therefore, he/she is unable to describe clearly the landscape inside the forest. Before the 1990s, the Chinese public have gone into the forest every day to pick up such living and production materials as mushrooms and branches, etc., however, as the modern technology continues developing and the urbanization keeps accelerating, people have been moving into cities that are far away from the forest and they do not have to get the fuel from it for daily life, which has resulted in lower frequencies of accessing to the forest, thus the lower accessibility of it. In addition, researches have shown that most of the graduate students interviewed are from Hunan, Guangxi and Jiangxi, etc. which belong to the terrain of hills, yet they have used relatively less distant views or bird's-eye views in the drawings, which indicates that the effect of the terrain on the spatial view is less than that of the distance and the accessibility to the forest.

On the aspect of the self-orientation and the social meaning, the drawings from the Chinese graduate students are dominated by the description of the objective scene and the scenic view, which indicates that there exists perceptual distance between them and the forest, and that they have not realized the interaction between people and the forest, and prefer rural forest landscape very much. This is the result of the following three affecting factors: the first one is the 
urbanization rate which has induced those people having lived in the city for a long time to feel homesick for the rural landscapes and homes around the forest with the increase of China's urbanization rate from $30.89 \%$ to $58.52 \%$ from 1999 to 2017 , therefore, they have unconsciously regarded the rural landscape that they are much interested in as the forest landscape by painting houses with chimneys. The second one is the style of traditional landscape drawings as the Eastern landscape painting adopts various viewing points and is good at combining the foreground and background to depict beautiful rural landscapes $[8,14]$. The third one is the cognition of the forest's value attribute, as according to the cognitive conception, the feature of the forest as the space for timber production is more often emphasized so as to highlight the natural attribute, while that of the forest as the space for the supply of public ecological products is neglected, which reduces the social attribute of the interaction between the forest and people [18]. Researches have shown that the public of Russia prefer the natural resources so prominently that they use mushrooms and berries as featured landscape elements to indicate that the forest is an important space for resources of traditional living materials; instead, the public of Japan prefer the surrounding space and the recreational space prominently, as they have frequent forest recreation and experience activities, and they like to put their position inside the forest and the ongoing recreation activities into the drawings to indirectly indicate that the forest is accessible and is an important external recreation space [8].

Therefore, on the base of the in-depth analysis of the linguistic knowledge, the spatial view, the self-orientation and the social meaning demonstrated in the drawings by China's graduate students above, and by referring to the existing related research results, this paper has tentatively established the forest landscape image mode of China's graduate students, as shown in Figure 
5.

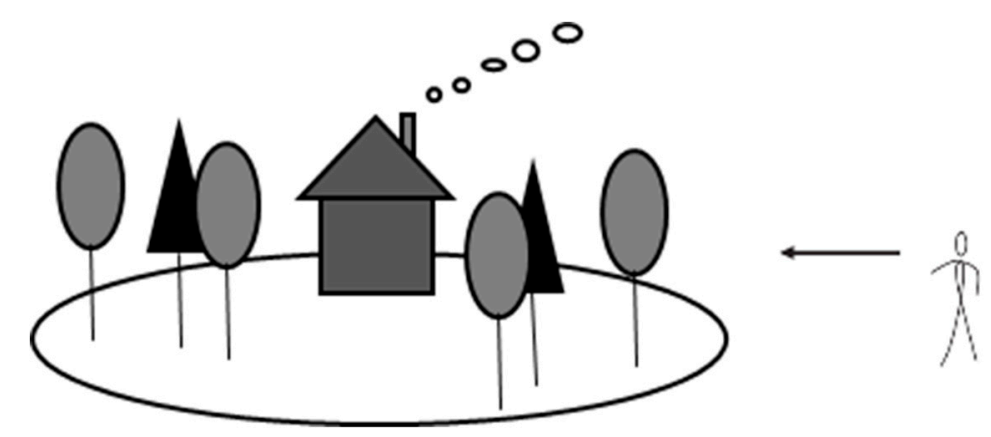

Figure 5. Forest landscape image for the young people in China

\section{Conclusions and Suggestions}

Based on the landscape image sketching technique, this paper has destructed the drawings of the forest landscape image from four dimensions, namely the linguistic knowledge, the spatial view, the self-orientation and the social meaning, to reach three cognitive conclusions of the forest as follows: (1) The forest is regarded as a representation of people's life world and of the rural landscape around homes, instead of an objective perception of the forest. Such linguistic knowledges of the forest landscape as the broadleaf forest, sky, objective scene, scenic view, and artificial view, etc. are all the description of beautiful forest landscape. (2) The forest is regarded as an important habitat and a limited space to satisfy the needs of people's life, production and recreation, into which people will go only when they have such demands, therefore, the graduate students have chosen to watch the beauty of forests from the perceptive of the sideways view, and have neglected the landscape combination inside the forest and the broadness of the forest. (3) Such natural values as the ecology and aesthetics attributes of the 
forest have got high attentions, for example, contents like the forest structure, the ecological system and the scenic view, etc. have become the focus of graduate students, in essence, such social values as the life, production and culture attributes of the forest have got low attentions, for example, the natural resources, the symbolic place and the forest operation, etc.

The main suggestions for implementing the forestry development theory of "lucid waters and lush mountains are invaluable assets" and making better use of China's rich forest resources to serve the strategic development of the forest tourism are as follows: (1) Strengthening people's awareness of the objective entity of forest and make full use of the forest tourism site of various levels and types that are represented by national forest parks, and vigorously promote the knowledge of popular science in forest ecology to the public with children and teenagers as the starting point by employing such key contents of the popular science in forest ecology as the forest tourism attractions inside the forest, the forest structure and ecological system, the forest operation and traditional applications. (2) Constructing a comprehensive forest education system for all the people, organize and lead the public to really walk into the forest, recognize the forest as a holly animal habitat, not a place for life and recreation, introduce laws and regulations related to the forest education, develop various education modes such as the outside recreation, the forest school, the forest kindergarten and the environmental interpretation, etc., and establish the brand of "forest classroom". (3) Building up a diversified forest experience system for people to acquire social, human and technological knowledges and skills in a free and open natural environment as the high quality experience is the soul of the sustainable development of the forest tourism, understand the effect and status of natural resources in the society, and improve the quality of the forest experience of the public through various 
sensations which can help transform the way graduate students look at the forest and enhance their perception of the forest. In addition, there are some shortcomings in this paper: firstly, the choice of the subtropical evergreen broadleaf forest area of Changsha as a case for the case study might affect the respondents' preference to the forest type because of the native environment that the respondents belong to; secondly, the overall sample quantity is so small that it needs to enlarge the population size of the respondents in future researches; thirdly, some respondents cannot paint exactly the scene in their minds due to their limited drawing abilities, which might result in the failure to represent some landscape elements and the error in the analysis results.

Author Contributions: Conceptualization, F.L. and Y.Z.; Investigation, C.W. and X.L.; Writing, C.W., F.L. and X.L.; Funding Acquisition, F.L. and Y.Z.

Funding: This research was funded by the Key Research Foundation of Education Bureau of Hunan Province, China (Grant No.18A164), the Key Research and Development Planning Project of Hunan Province, China (Grant No. 2016SK2024), and the Philosophical and Social Science Foundation of Hunan Province, China (Grant No. 17JD87).

Acknowledgments: We thank Mohamed Gazali Ahmed for its linguistic assistance during the preparation of this manuscript.

Conflicts of Interest: The authors declare no conflict of interest.

\section{References}

1. Xi, J.P. To win the great victory of socialism with Chinese characteristics in the new era 
by building a well-off society in an all-round way. People's Daily, 2017-10-19.

2. Luo, F.; Li, X.L.; Li, S.X.; He, J.W. Literature review on public preference for forest structure attributes. Forest Resources Management 2018, 3, 133-140, doi:10.13466/j.cnki.lyzygl.

3. Zhong, Y.D.; Chen, X.F. Forestry tourism is the top earner of forestry in the United States. China Green Times, 2015-09-15.

4. Braun, A. Wahrnehmung von Wald und Natur; VS Verlag für Sozialwissenschaften: Wiesbaden,DE, 2000; pp. 58, ISBN 978-3-663-11806-0.

5. Seeland, K. Der Wald als Kulturphänomen : von der Mythologie zum Wirtschaftsobjekt. Geographica Helvetica 2018, 48, 61-66, doi:10.5194/gh-48-61-1993.

6. Schroeder, H.W. Place experience, gestalt, and the human-nature relationship. Journal of Environmental Psychology 2007, 27, 293-309, doi:10.1016/j.jenvp.2007.07.001.

7. Cloke, P.; Milbourne, P.; Thomas, C. The English National Forest: Local Reactions to Plans for Renegotiated Nature-Society Relations in the Countryside. Transactions of the Institute of British Geographers 1996, 21, 552-571, doi:10.2307/622596.

8. Ueda, H.; Nakajima, T.; Takayama, N.; Petrova, E.; Matsushima, H.; Furuya, K.; Aoki, Y. Landscape image sketches of forests in Japan and Russia. Forest Policy \& Economics 2012, 19, 20-30, doi:10.1016/j.forpol.2012.01.002.

9. Junge, X.; Schüpbach, B.; Walter, T.; Schmid, B.; Lindemann-Matthies, P. Aesthetic quality of agricultural landscape elements in different seasonal stages in Switzerland. Landscape \& Urban Planning 2015, 133, 67-77, doi:10.1016/j.landurbplan.2014.09.010. 
10. Lindhagen, A. An approach to clarifying public preferences about silvicultural systems: a case study concerning group selection and clear-cutting. Scandinavian Journal of Forest Research 1996, 11, 375-387, doi:10.1080/02827589609382950.

11. Edwards, D.; Jay, M.; Jensen, F.S.; Lucas, B.; Marzano, M.; Montagné, C.; Peace, A.; Weiss, G. Public preferences for structural attributes of forests: Towards a pan-European perspective. Forest Policy \& Economics 2012, 19, 12-19, doi:10.1016/j.forpol.2011.07.006.

12. Coles, R.W.; Bussey, S.C. Urban forest landscapes in the UK - progressing the social agenda. Landscape \& Urban Planning 2000, 52, 181-188, doi:10.1016/S01692046(00)00132-8.

13. Ueda, H. Landscape Perception in Japan and Germany. In Basic and clinical environmental approaches in landscape planning, Springer: Tokyo, JPN, 2014; pp. 1524, ISBN 978-4-431-54415-9.

14. Kaplan, S. Aesthetics, affect, and cognition: Environmental preference from an evolutionary perspective. Environment and behavior 1987, 19, 3-32, doi:10.1177/0013916587191001.

15. Zube, E.H.; Sell, J.L.; Taylor, J.G. Landscape perception: Research, application and theory. Landscape Planning 1982, 9, 1-33, doi:10.1016/0304-3924(82)90009-0.

16. Chen, X.; Yan, W. An analytic study on forest beauty_mostly on form beauty of forest plants. Scientia Silvae Sinicae 2001, 37, 122-130, doi:10.11707/j.10017488.20010220.

17. Chen, X.; Jia, L. Research on evaluation of in-forest landscapes in west Beijing 
mountain area. Scientia Silvae Sinicae 2003, 39, 59-66, doi:10.1007/BF02974893.

18. Luo, F.; Moyle, B.D.; Bao, J.; Zhong, Y. The role of institutions in the production of space for tourism: National Forest Parks in China. Forest Policy \& Economics 2016, 70, 47-55, doi:10.1016/j.forpol.2016.05.021.

19. Mao, B.; Cheng-Yang, X.U.; Chen, Y.; Le, L.I. Application of Analytic Hiberarchy Process to the Evaluation of In-forest Landscape Quality in Scenic Forest. Journal of Northwest Forestry University 2014, 29, 204-209., doi:10.3969/j.issn.10017461.2014.03.41.

20. Mei, G.Y.; Sun, Y.J.; Lin, F.; Wang, Y.F. Study on evaluation index system of Cunninghamia lanceolata scenic and recreational forests based on analytic network process. Journal of Central South University of Forestry \& Technology 2013, 33, 110140., doi:10.14067/j.cnki.1673-923x.2013.02.024.

21. Jun-Ying, L.I.; Yan, H.W.; Tang, Q.; Zhu, Y. A scenic beauty estimation model for a natural secondary forest. Journal of Zhejiang Forestry College 2010, 27, 923-927, doi:10.3724/SP.J.1142.2010.40486.

22. Lynch, K. The Image of the City; Mit Press: Cambridge, UK, 1960; pp. 3, ISBN 97802-6262-001-7.

23. Liu, B.Y.; C., G. On the construction of tourist experience behavior environment based on regional landscape image. Economic Research Guide 2011, 35, 81-83., doi:10.3969/j.issn.1673-291X.2011.35.034.

24. Waterman, J.T. Language, Thought, and Reality: Selected Writings of Benjamin Lee Whorf by John B. Carroll. Language 1956, 33, 421, doi:10.2307/411163. 
25. Ueda, H. A Study on Construction of Landscape Image Sketching Technique. Journal of the City Planning Institute of Japan 2009, 44, 37-42, doi: https://doi.org/10.11361/journalcpij.44.3.37.

26. Ueda, H. A comparative study on forest image in Japan and German. Journal of the Japanese Institute of Landscape Architecture 2006, 67, 691-694, doi:10.5632/jila.69.691.

27. Lee, T.R. Perceptions, attitudes and preferences in forests and woodlands; Forestry Commission Technical Paper 18. : Edinburgh, United Kingdom, 2001; pp. 21, ISBN 085538-345-3.

28. Tyrväinen, L.; Pauleit, S.; Seeland, K.; de Vries, S. Benefits and uses of urban forests and trees. In Urban forests and trees, Springer: Berlin, DE, 2005; pp. 81-114, ISBN 3540-25126-X.

29. Engelmark, O. Multiple-use forestry in the Nordic countries. Forest Ecology \& Management 1998, 102, 339-340, doi:http://dx.doi.org/10.1016/S0378-1127(97)00218$\underline{1}$.

30. Rydberg, D.; Falck, J. Urban forestry in Sweden from a silvicultural perspective: a review. Landscape \& Urban Planning 2000, 47, 1-18, doi:10.1016/S01692046(99)00068-7.

31. Nisbet, E.K.; Zelenski, J.M.; Murphy, S.A. The nature relatedness scale: Linking individuals' connection with nature to environmental concern and behavior. Environment and Behavior 2009, 41, 715-740, doi:10.1177/0013916508318748.

32. Tang, I.-C.; Sullivan, W.C.; Chang, C.-Y. Perceptual evaluation of natural landscapes: 
The role of the individual connection to nature. Environment and Behavior 2015, 47, 595-617, doi:10.1177/0013916513520604.

33. Ribe, R.G. The aesthetics of forestry: What has empirical preference research taught us? Environmental Management 1989, 13, 55-74, doi:10.1007/BF01867587.

34. Purcell, T.; Peron, E.; Berto, R. Why do preferences differ between scene types? Environment and behavior 2001, 33, 93-106, doi:10.1177/00139160121972882.

35. Hunziker, M.; Felber, P.; Gehring, K.; Buchecker, M.; Bauer, N.; Kienast, F. Evaluation of Landscape Change by Different Social Groups. Mountain Research \& Development 2008, 28, 140-147, doi:10.1659/mrd.0952.

36. Wan, J.A.; Yong, C. The Development of Forest Education In developed countries and Educational Implications. Primary \& Secondary Schooling Abroad 2013, 8, 35-38., doi:10.3969/j.issn.1007-8495.2013.08.006.

37. Luo, F.; Zhang, A.N.; Qu, P.Y.L., L.;; Wang, G.M. Mode of forest environmental education for children in Europe. Journal of Central South University of Forestry \& Technology(Social Sciences) $\quad$ 2016, 10, 56-61, doi:10.14067/j.cnki.16739272.2015.06.011.

38. Chawla, L. Life paths into effective environmental action. The Journal of Environmental Education 1999, 31, 15-26, doi:10.1080/00958969909598628.

39. Nisbet, E.K.; Zelenski, J.M. Underestimating nearby nature: Affective forecasting errors obscure the happy path to sustainability. Psychological science 2011, 22, 1101-1106, doi:10.1177/0956797611418527.

40. Petrova, E.G.; Mironov, Y.V.; Aoki, Y.; Matsushima, H.; Ebine, S.; Furuya, K.; Petrova, 
A.; Takayama, N.; Ueda, H. Comparing the visual perception and aesthetic evaluation of natural landscapes in Russia and Japan: cultural and environmental factors. Progress in Earth \& Planetary Science 2015, 2, 6, doi:10.1186/s40645-015-0033-x. 